\title{
Synchrotron X-ray Absorption Spectroscopic Investigation of Uranyl-Chloride Aqueous Solutions at Hydrothermal Conditions
}

J. BAKER ${ }^{* 1}$, N. AKRAM ${ }^{2}$, D. DHAKAL ${ }^{2}$, R. MAYANOVIC ${ }^{2}$, X. GUO ${ }^{3}$, X. ZHANG ${ }^{1}$, M. KelleY ${ }^{1}$, E. BATISTA ${ }^{1}$, P. $^{2}$

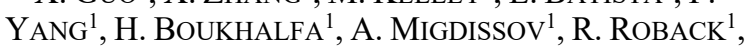
C-J. SUN ${ }^{4}$, AND H. XU ${ }^{1}$

${ }^{1}$ Los Alamos National Laboratory (*correspondence: jlbaker@lanl.gov)

${ }^{2}$ Missouri State University

${ }^{3}$ Washington State University

${ }^{4}$ Argonne National Laboratory

Understanding chemical speciation and coordination of actinides in aqueous solutions at hydrothermal conditions is crucial to addressing a variety of environmental issues surrounding actinides such as their mobility at conditions of nuclear accidents (e.g. Fukushima disaster) and their behavior in high-level nuclear waste disposal in underground repositories. Of specific interest are actinide-bearing aqueous solutions containing ligands potentially found in these environments such as $\mathrm{Cl}^{-}, \mathrm{SO}_{4}{ }^{2-}$, and $\mathrm{CO}_{3}{ }^{2-}$ which can complex with actinide ions at high temperatures and pressures.

The coordination environment of $\mathrm{UO}_{2}{ }^{2+}$ was probed with a combination of theoretical modeling and X-ray absorption spectroscopy (XAS), a powerful tool to characterize oxidation state and coordination environments. In this study, we performed in-situ U L-III edge XAS measurements on $\mathrm{UO}_{2}{ }^{2+}-\mathrm{Cl}^{-}$aqueous solutions $\left(\left[\mathrm{UO}_{2}{ }^{2+}\right]=50 \mathrm{mM},\left[\mathrm{Cl}^{-}\right]=1 \mathrm{M}, 3 \mathrm{M}\right.$, $6 \mathrm{M}]$ ) at the Advanced Photon Source and the Stanford Synchrotron Radiation Lightsource. Room temperature to $500{ }^{\circ} \mathrm{C}$ was explored using a hydrothermal diamond anvil cell with a specially designed radiation enclosure [1]. Our theoretical modeling using density functional theory (DFT) predicts that at $25^{\circ} \mathrm{C}, \mathrm{UO}_{2}{ }^{2+}$ coordinates with 5 equatorial $\mathrm{H}_{2} \mathrm{O}$ surrounding the $\mathrm{U}$ atom whereas at increased temperatures, the calculations predict $\mathrm{Cl}^{-}$to coordinate, replacing the $\mathrm{H}_{2} \mathrm{O}$. Using the DFT optimized models, analysis of the extended X-ray absorption fine structure region (EXAFS) below $200^{\circ} \mathrm{C}$ revealed a change in chemical coordination of the $\mathrm{UO}_{2}{ }^{2+}$ from 5-coordinated $\mathrm{H}_{2} \mathrm{O}$ to 3-4coordinated $\mathrm{H}_{2} \mathrm{O}$ and 1-2-coordinated $\mathrm{Cl}^{-}$. At temperautres above $200^{\circ} \mathrm{C}$, examination of the X-ray absorption near edge structure (XANES) region of our XAS spectra, we observed a possible $\mathrm{X}$-ray induced reduction from $\mathrm{U}^{6+}$ to $\mathrm{U}^{4+}$.

[1] Dhakal et al. (2019) Rev. Sci. Instrum. 90, 083108. 